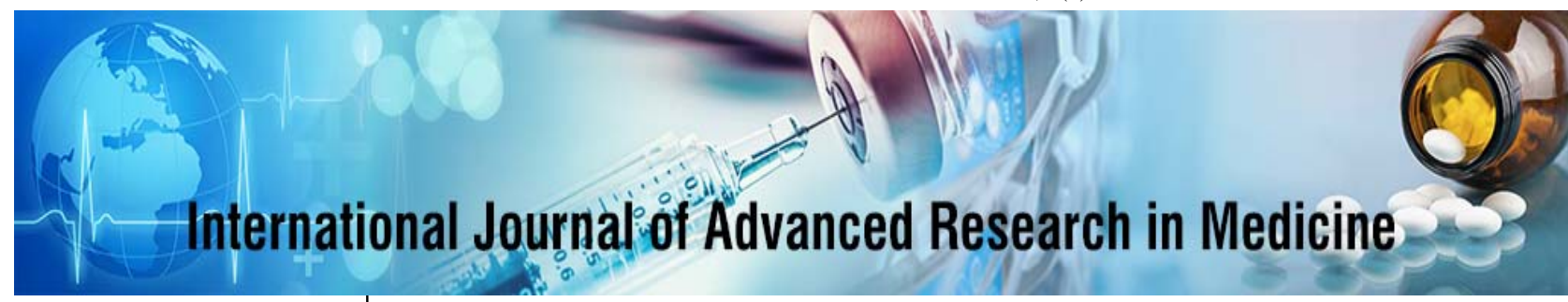

E-ISSN: 2706-9575 P-ISSN: 2706-9567 IJARM 2020; 2(2): 32-38 Received: 13-05-2020 Accepted: 16-06-2020

Dr. Syeda Parveen Fatima Assistant Professor, Department of Physiology, Ayaan Institute of Medical, Sciences, Kankamidi (V), Moinabad (M), Ranga Reddy District, Telangana, India

Corresponding Author: Dr. Syeda Parveen Fatima Assistant Professor, Department of Physiology, Ayaan Institute of Medical, Sciences, Kankamidi (V), Moinabad (M), Ranga Reddy District, Telangana, India

\title{
Study of pulmonary function test in chronic renal failure and the effect of hemodialysis
}

\section{Dr. Syeda Parveen Fatima}

DOI: https://doi.org/10.22271/27069567.2020.v2.i2a.47

\section{Abstract}

Background: Renal failure is the condition where the kidneys fail to function properly Treatment options for renal failure are medical management and renal replacement therapy. Renal replacement therapy includes hemodialysis, peritoneal dialysis and renal transplantation. Pulmonary complications of renal disease are extensively studied and well documented. Therefore this study was undertaken to evaluate the lung function tests in chronic renal failure cases and the effect of hemodialysis on lung function.

Aim \& objective: In this present study pulmonary function tests of chronic renal failure patients were compared with the normal healthy adults by the computerized spirometric values.

Methodology: This is prospective comparative observation study was conducted in a total of 60 patients at the Clinical Physiology Lab, Department of Physiology, Deccan Medical College and in the Nephrology ward at Owaisi Hospital and Research Centre - Hyderabad, during the year June 2013 to September 2014.

Results: The lung function parameters in chronic renal failure are significantly reduced than the normal subjects. The lung function parameters were also measured in chronic renal failure who were undergoing regular hemodialysis A small but significant improvement in FVC, FEV1, FEV1\%, PEF and FEF25- 75\% was noticed consistently in most of the patients after hemodialysis. Though the improvement is more marked during 1 week of hemodialysis therapy, the values steadily and slowly improved after 3 months of hemodialysis therapy but was significantly lower than the normal values. None of our patients attained even near normal values at the end of 3 months of hemodialysis. Blood parameters like blood urea and serum creatinine levels were significantly reduced in repeated hemodialysis.

Conclusion: This study reconfirms the already established fact of restrictive type of ventilatory defect in chronic renal failure patients this study has reflected the effects of hemodialysis on pulmonary function test in chronic renal failure patients over a short duration.

Keywords: chronic renal function, hemodialysis, pulmonary function

\section{Introduction}

Diseases of the kidneys are among the most important causes of death and disability in many countries throughout the world. The overall incidence of end stage renal disease is 260 cases per million populations. There are nearly 70 million people with kidney disease of varying severity levels in India. The incidence is higher in elderly age group ten times more than under 40 years of age and it is also higher in males compared to females (1.3:1). The mortality of patients with the End Stage Renal Disease (ESRD) is very high in developing world because of the limited availability of dialysis therapy.

Renal failure is the condition where the kidneys fai! to function properly. The kidney has the ability to filter the plasma and remove substances from the filtrate at variable rates depending on the needs of the 'body which is called the Glomerular Filtration Rate (GFR). Physiologically, renal failure is described as a decrease in the glomerular filtration rate. Clinically, this manifests as an elevated blood urea nitrogen and serum creatinine level.

Renal failure can be classified into an acute and chronic renal failure. Hypertension and diabetes are the two main causative factors for chronic renal failure. The mortality rate of chronic renal failure is 22.4/100 patients per year. The chronic renal failure may affect virtually every system in the body including the lungs.

A functionally intact respiratory system is of vital importance for the patients with renal insufficiency. The pulmonary system is unique because it is affected by the renal disease and 
its treatment. In chronic renal failure patients, pulmonary edema and pleural effusions attributed to fluid overload and an increase in pulmonary capillary permeability are relatively common. These complications reduce the pulmonary function which is reflected as low vital capacity, forced expiratory volume, lung diffusing capacity and maximal mid expiratory rate. Rare complications include pulmonary fibrosis and calcification, pulmonary hypertension, hemosiderosis, pleuritis and pleural fibrosis.

Treatment options for renal failure are medical management and renal replacement therapy. Renal replacement therapy includes hemodialysis, peritoneal dialysis and renal transplantation.

Pulmonary complications of renal disease are extensively studied and well documented. But little is known about the effects of different forms of renal replacement therapy on lung function. Therefore this study was undertaken to evaluate the lung function tests in chronic renal failure cases and the effect of hemodialysis on lung function.

\section{Aims and objectives}

- To assess the pulmonary functions in chronic renal failure patients.

- To study the effect of hemodialysis on lung functions in chronic renal failure patients.

- To compare the levels of renal parameters like blood urea, serum creatinine and serum albumin levels before and after hemodialysis.

- I o study the changes in weight, blood pressure and hemoglobin \% of the chronic renal failure patients before and after hemodialysis.

- To study the effect of gender on pulmonary functions in chronic renal failure patients.

\section{Materials and methods \\ Study place}

This study was conducted in the Clinical Physiology Lab, Department of Physiology, Deccan Medical College and in the Nephrology ward at Owaisi Hospital and Research Centre - Hyderabad

\section{Study period}

June 2013 to September 2014.

\section{Study subjects}

The patients were selected from the Nephrology ward, at Owaisi Hospital and Research Centre after getting permission from the head of the department.

A total of 60 subjects were recruited for this study in both sexes in the age of 45 - 60 years. (32 male and 28 female). The subjects were divided into two groups.

1. Control Group

2. Study Group

Control group comprised of 30 healthy volunteers (14 males and 16 females).

Study group comprised of 30 adults (18 males and 12 females) diagnosed to have chronic renal failure under standard criteria who were planned for renal replacement therapy of hemodialysis.

The study group was subdivided into 2(A), 2(B), (2C), 2(D), (2E) and 2(F) depending on the duration of hemodialysis. 2(A) - Predialysis (chronic renal failure patients)

2(B) - One dialysis 2(C) - 1 Week dialysis 2(D) - 1 Month dialysis 2(E) - 2 Months dialysis 2(F) - 3 Months dialysis

\section{Frequency of dialysis being 3 per week}

The procedure of the study was explained in detail and written consent was obtained from both control and study group for involving them in the study.

\section{Inclusion Criteria}

Signs and symptoms of renal failure more than 2 months in duration.

Serum creatinine $>1.5 \mathrm{mgs} \%$

Blood urea $>60 \mathrm{mgs} \%$

Patients of chronic renal failure diagnosed under clinical criteria

Who were all planned for the treatment modality of hemodialysis therapy

\section{Exclusion Criteria}

- Patients with pre-existing lung disease.

- History of smoking and alcohol.

- Patients with cardiac disease.

- Family history especially in relation to respiratory disorders like asthma, allergies, history of contact with open tuberculosis.

\section{Materials used for this study}

1. Examination proforma used for recording the clinical examination findings was designed and validated.

2. Computerised data logging Spirometer for recording pulmonary function tests (Spirobank - G).

3. Portable weighing machine - torecord the body weight in kilograms.

4. Measuring Tape - to measure the standing height in centimeters.

5. Standard sphygmomanometer - for measuring the blood pressure.

6. Standard haemoglobinometer for measuring HB\%.

7. Standard auto analyzer (Erba xL 300) and specific kit for measuring blood urea, serum creatinine and serum albumin.

Methodology

1. A detailed history was obtained and recorded from control and study group in the prescribed proforma.

2. Height (ems) of the subjects was measured in standing and erect posture.

1. The following parameters were recorded before and after each sitting of

hemodialysis such as 1 day, 1 week, 1 month, 2 months and 3 months duration of repeated dialysis.

2. Weight (kgs)

3. Blood pressure (mmHg)

4. Blood parameters - HB\%, blood urea, serum creatinine and serum albumin.

5. Pulmonary function tests.

Weight: recorded using standard weighing machine both for control group and chronic renal failure patients (pre dialysis and post dialysis period) in standing posture.

Blood pressure: blood pressure of the subjects was measured on lying posture before and after each sitting of the dialysis by using the Sphygmomanometer. 


\section{Blood parameters haemoglobin}

Haemoglobin level was measured in gram \% by Sahlis method. N/10 HCL was taken up to the lowest level in the haemoglobin tube. 20 cumm of blood sample was taken in the haemoglobin pipette. It was mixed with N/10 FICL in haemoglobin tube and waited for $10 \mathrm{~min}$ for haematin formation. After that distilled water was added drop by drop and the colour of the solution was matched with the comparator stand. The haemoglobin level was measured from the haemoglobin tube in grams\%.

\section{Blood urea}

Blood urea level was estimated by modified diacetyl monoxime method. Plasma was prepared from the blood sample by centrifugation. 10 micro lits of plasma was taken into the test tube. $1.5 \mathrm{ml}$ of dam (diacetyl monoxime) reagent and $2 \mathrm{~m} 1$ of acid reagent were added to it. The solution was mixed well and kept in boiled water for $15 \mathrm{mins}$. The readings were taken at 540 $\mathrm{nm}$ in calorimeter.

\section{Serum creatinine}

Serum was prepared from the venous blood sample by centrifugation. 50 micro lits. of serum was taken in a test tube and mixed with 500micro lit. of creatinine reagent. The test tube which contains the solution was kept in autoanalyser for 50 secs. The reading was taken directly from the auto analyzer itself

\section{Serum albumin}

Serum albumin was measured in gram \% using an auto analyzer. Serum was prepared from the blood sample by centrifugation. 5 micro lits. of serum was taken in the test tube. It was mixed with 500 micro lits. of albumin reagent. The test tube which contains the solution was kept in the auto analyzer. The reading was taken immediately.

\section{Technique of pulmonary function tests}

Pulmonary function tests were done in forenoon before dialysis and within 24 hours of dialysis in the sitting posture of the patient. It was carried out using Spirobank with built in computer program. It is a small compact instrument. It consists of air blow pipe with electronic transducer, operating key board, a monitor to read the values on the screen and a printer to get the results.

The patients were informed about the instrument and the procedure of the test was explained in detail. The data of the subjects regarding height in $\mathrm{cm}$, weight in $\mathrm{kg}$ and sex were fed into the spirometer. Disposable mouth piece was inserted into the protruding part of the spirobank and the following tests were done.

\section{FVC test}

The subject was asked to breathe at rest for a few moments then inspire fully as much as possible and then make a complete expiration as fast as possible, to complete the cycle by inspiring again as quickly as possible.

\section{Parameters recorded during FVC test}

FVC (Forced Vital Capacity), FEV1 (Forced Expiratory volume at the end of 1 second), PEF (Peak Expiratory Flow), FEV1\%, FEF25-75\% (Forced Expiratory Flow2575\%), PIF (Peak Inspiratory Flow).

Parameters recorded during VC test FEV1\%, VC, ERV (Expiratory Reserve Volume), TV (Tidal Volume), VE (minute ventilation at rest) FR (Respiratory frequency), $\mathrm{TI}$ (Average time of inspiration at rest), TE(Average time of expiration at rest), TI/TE, TV/TI.

Three trials were given to each test after $15 \mathrm{~min}$. interval. The best spirometric values of three attempts were taken. A complete flow volume loop was obtained from the spirometer. The spirogram (flow volume loop) was directly down loaded from the instrument and printed. The results obtained were tabulated and analysed.

\section{Hemodialysis}

Patients subjected to hemodialysis were transferred to the dialysis unit. A large bore double lumen cannula was inserted into a central vein under local anaesthesia. Jugular vein (or) femoral vein (or) subclavian vein was selected for this purpose. Before the dialysis, injection heparin was administered and this served as an anticoagulant. Catheter based vascular access was connected to the dialysis machine. The dialysis machine comprises of a series of blood pumps with pressure monitors, bubble detectors and blood leak detectors. Uraemic blood from the patient is pumped into the dialyzer and the blood is purified (unwanted toxic products are removed). The purified blood is returned back to the patient's general circulation. During dialysis, blood flow is adjusted to about $200-300 \mathrm{~m} 1 / \mathrm{min}$. Dialysate flow is adjusted to a rate of $500 \mathrm{~m} 1 / \mathrm{min}$. Dialysis frequency and duration are adjusted according to the severity of the symptoms and biochemical parameters of the patient. Usually dialysis is done for 4-5 hours three times a week. If the patient has considerable residual renal function, twice weekly dialysis is adequate.

\section{Statistical analysis}

Mean and Standard deviation were calculated. Studener test has been carried out to test the significance of mean between the control group and study group.

To test the significant difference of means within the dialysis group was analyzed using one way Po, NOVA. It was also applied to test the significant difference of means among the control group, pre-dialysis and 3 months of hemodialysis group. Post hoc comparisons were done using least significant different methods.

\section{Results and analysis}

For this study 30 normal subjects and 30 chronic renal failure patients were selected; Normal subjects were considered as group 1. Chronic renal failure (CRF) patients were considered as group2. Chronic renal failure patients were again categorized into Group 2(A), 2(B), 2(C), 2(D), 2(E) and 2(F) based on the duration of hemodialysis.

Table 1: Frequency of dialysis 3 Dialysis / Week

\begin{tabular}{|c|c|}
\hline Group & Status \\
\hline 1 & Healthy adults (control) \\
\hline 2 & Chronic renal failure patients \\
\hline $2(\mathrm{~A})$ & Pre-dialysis \\
\hline $2(\mathrm{~B})$ & 1 Dialysis \\
\hline $2(\mathrm{C})$ & 1 Week Dialysis \\
\hline $2(\mathrm{D})$ & 1 Month Dialysis \\
\hline $2(\mathrm{E})$ & 2 Month Dialysis \\
\hline $2(\mathrm{~F})$ & 3 Month Dialysis \\
\hline
\end{tabular}


Table 2: Anthropometric measurement of group 1 and 2

\begin{tabular}{|c|c|c|c|c|}
\hline \multirow{2}{*}{ Parameters } & \multicolumn{2}{|c|}{ Range } & \multicolumn{2}{c|}{ Means + SD } \\
\cline { 2 - 5 } & Control & CRF & Control & CRF \\
\hline Age (yrs) & $45-60$ & $45-60$ & $50.73+4.7$ & $50.96+5.5$ \\
\hline Height(cms) & $145-175$ & $145-175$ & $161.43+6.6$ & $161.6+8.6$ \\
\hline Weight (kgs) & $42-70$ & $41-70$ & $53.7+5.9$ & $54.9+7.8$ \\
\hline
\end{tabular}

Table 2: Group 1 (control) parameters

\begin{tabular}{|c|c|c|}
\hline Parameters & Means & SD \\
\hline Vital Capacity (VC) (L) & 3.36 & 0.72 \\
\hline Forced Vital Capacity (FVC) (L) & 3.15 & 0.7 \\
\hline Forced Expiratory Volume at one second (FEV1) (L) & 2.886 & 0.7 \\
\hline FEV1 \% (FEV1/FVC X 100) (L/S) & 91.3 & 3.3 \\
\hline Peak Expiratory Flow (PEF) (L/S) & 3.07 & 1.84 \\
\hline Forced Expiratory Flow 25-75\% (FEF25-75\%) (L/S) & 3.19 & 0.9 \\
\hline Weight (Kgs) & 53.7 & 5.9 \\
\hline Systolic Blood pressure (mmHg) & 125.6 & 7.6 \\
\hline Diastolic Blood pressure (mmHg) & 83.6 & 4.5 \\
\hline Hemoglobin (gms \%) & 12.9 & 1.0 \\
\hline Blood Urea (mgs \%) & 29.3 & 3.2 \\
\hline Serum creatinine (mgs \%) & 0.95 & 0.2 \\
\hline Serum Albumin (gms \%) & 3.17 & 0.2 \\
\hline
\end{tabular}

Table 3: Effect of hemodialysis on vc and FVC In CRF patients

\begin{tabular}{|c|c|c|c|c|}
\hline \multirow{2}{*}{ Group } & \multicolumn{2}{|c|}{ VC(L) } & \multicolumn{2}{c|}{ FVC(L) } \\
\cline { 2 - 5 } & Mean & SD & Mean & SD \\
\hline $2(\mathrm{~A})$ & 1.7 & 0.6 & 1.7 & 0.5 \\
\hline $2(\mathrm{~B})$ & 1.7 & 0.6 & 1.7 & 0.5 \\
\hline $2(\mathrm{C})$ & 1.9 & 0.6 & 1.8 & 0.5 \\
\hline $2(\mathrm{D})$ & 2.0 & 0.6 & 2 & 0.6 \\
\hline $2(\mathrm{E})$ & 2.1 & 0.6 & 2.1 & 0.6 \\
\hline $2(\mathrm{~F})$ & $2.2^{*}$ & 0.6 & $2.3^{*}$ & 0.6 \\
\hline
\end{tabular}

$P<0.05$ was significant, $* \mathrm{p}=0.000$

Vital capacity and forced vital capacity values decreased in chronic renal failure patient with serial hemodialysis, the vital capacity and forced vital capacity improved gradually to a significant value after 3 month of repeated hemodialysis when compared to the pre-dialysis value.

Table 4: Effect of hemodialysis on fev1 in CRF patients

\begin{tabular}{|c|c|c|}
\hline \multirow{2}{*}{ Group } & \multicolumn{2}{|c|}{ FEV1 (L) } \\
\cline { 2 - 3 } & Mean & SD \\
\hline $2(\mathrm{~A})$ & 1.4 & 0.5 \\
\hline $2(\mathrm{~B})$ & 1.4 & 0.4 \\
\hline $2(\mathrm{C})$ & 1.5 & 0.5 \\
\hline $2(\mathrm{D})$ & 1.7 & 0.5 \\
\hline $2(\mathrm{E})$ & $1.9^{*}$ & 0.5 \\
\hline $2(\mathrm{~F})$ & $2.1^{*}$ & 0.5 \\
\hline
\end{tabular}

The mean Forced Expiratory volume at the end of one second was low in chronic renal failure patients. A drastic improvement of FEV 1 value was seen in 3 months of hemodialysis.

Table 5: Effect of hemodialysis on FEV1\% in CRF patients

\begin{tabular}{|c|c|c|}
\hline \multirow{2}{*}{ Group } & \multicolumn{2}{|c|}{ FEV1 \% } \\
\cline { 2 - 3 } $2(\mathrm{~A})$ & Mean & SD \\
\hline $2(\mathrm{~B})$ & 79.3 & 2.9 \\
\hline $2(\mathrm{C})$ & $80.3^{*}$ & 3.0 \\
\hline $2(\mathrm{D})$ & $83.4^{*}$ & 3.2 \\
\hline $2(\mathrm{E})$ & $86.7^{*}$ & 3.4 \\
\hline $2(\mathrm{~F})$ & $89.8^{*}$ & 3.3 \\
\hline${ }^{*} \mathrm{p}=0.000$ & $92.5^{*}$ & 3.5 \\
\hline
\end{tabular}

FEV1\% value improved from 1 week hemodialysis onwards. A remarkable improvement was seen in 3rd month of hemodialysis.

Table 6: Effect of hemodialysis on FEV in CRF patients

\begin{tabular}{|c|c|c|}
\hline \multirow{2}{*}{ Group } & \multicolumn{2}{|c|}{ PEF(L/S) } \\
\cline { 2 - 3 } & Mean & SD \\
\hline $2(\mathrm{~A})$ & 1.63 & 0.18 \\
\hline $2(\mathrm{~B})$ & 1.72 & 0.81 \\
\hline $2(\mathrm{C})$ & $2 *$ & 1.8 \\
\hline $2(\mathrm{D})$ & 2.29 & 0.77 \\
\hline $2(\mathrm{E})$ & $2.55^{*}$ & 0.76 \\
\hline $2(\mathrm{~F})$ & $2.79^{*}$ & 0.74 \\
\hline${ }^{*} \mathrm{p}=0.001$ & \multicolumn{2}{|}{} \\
${ }^{*} \mathrm{p}=0.000$ & \multicolumn{2}{|c}{}
\end{tabular}

PEF value revealed significant difference from 1 week dialysis and significantly higher values were recorded in 3rd month of hemodialysis.

Table 7: Effect of hemodialysis on FEV 25-75\% in CRF patients

\begin{tabular}{|c|c|c|}
\hline \multirow{2}{*}{ Group } & \multicolumn{2}{|c|}{ PEF25 -75\% (L/S) } \\
\cline { 2 - 3 } & Mean & SD \\
\hline $2(\mathrm{~A})$ & 1.3 & 0.5 \\
\hline $2(\mathrm{~B})$ & 1.4 & 0.5 \\
\hline $2(\mathrm{C})$ & 1.5 & 0.5 \\
\hline $2(\mathrm{D})$ & 1.6 & 0.5 \\
\hline $2(\mathrm{E})$ & $1.7 *$ & 0.5 \\
\hline $2(\mathrm{~F})$ & $1.9^{*}$ & 0.5 \\
\hline${ }^{*} \mathrm{p}=0.03$ & \multicolumn{2}{|c}{} \\
${ }^{*} \mathrm{p}=0.002$ & \multicolumn{2}{|c}{}
\end{tabular}

Low FEF25 -75\% in pre-dialysis group (CRF). Significant rise of FEF25 -75\% is seen after 3rd munth of hcatudialysis.

Table 8: Comparison of lung parameters among Group 1, 2(A) and 2(F)

\begin{tabular}{|c|c|c|c|c|c|c|c|c|}
\hline \multirow{2}{*}{ Parameter } & \multicolumn{2}{|c|}{ Group 1} & \multicolumn{2}{|c|}{ Group 2(A) } & \multirow{2}{*}{$\begin{array}{c}\text { P Value } \\
\text { Value }\end{array}$} & \multicolumn{2}{|c|}{ Group 2 (F) } & \multirow{2}{*}{$\begin{array}{c}\text { P Value } \\
\text { Value }\end{array}$} \\
\hline & Mean & SD & Mean & SD & & Mean & SD & \\
\hline VC (L) & 3.36 & 0.72 & 1.71 & 0.6 & 0.000 & 2.28 & 0.6 & 0.000 \\
\hline FVC (L) & 3.15 & 0.72 & 1.71 & 0.5 & 0.000 & 2.26 & 0.6 & 0.000 \\
\hline FEV1 (L) & 2.8 & 0.69 & 1.44 & 0.5 & 0.000 & 2.02 & 0.5 & 0.000 \\
\hline FEV 1\% & 91.3 & 3.25 & 79.3 & 0.9 & 0.000 & 92.5 & 3.5 & 0.180 \\
\hline PEF (L/S) & 3.07 & 1.84 & 1.63 & 0.8 & 0.000 & 2.79 & 0.7 & 0.001 \\
\hline FEF 25-75\% (L/S) & 3.19 & 0.88 & 1.36 & 0.5 & 0.000 & 1.89 & 0.5 & 0.000 \\
\hline
\end{tabular}

Group $=$ Control

Group 2 (A) = Chromic Renal Failure Group 2 (F) = 3 Month of Hemodialysis 
The Lung function values were significantly low in CRF patients when compared with control group. With regular hemodialysis for three months these values improved significantly but the values did not reach the level of the control group except FEV1\%.

Table 9: Effect of hemodialysis on blood pressure in CRF patients

\begin{tabular}{|c|c|c|c|c|}
\hline \multirow{2}{*}{ Group } & \multicolumn{2}{|c|}{ 'SBP (mmHg) } & \multicolumn{2}{c|}{ DBP (mmHp) } \\
\cline { 2 - 5 } & Mean & SD & Mean & SD \\
\hline 2(A) & 140.7 & 23.2 & 90.67 & 11.1 \\
\hline 2(B) & 136 & 17.9 & 87.3 & 8.7 \\
\hline 2(C) & 133.3 & 17.7 & 87.3 & 8.1 \\
\hline 2(D) & 131.3 & 3.8 & 85.7 & 6.7 \\
\hline 2(E) & 129 & 13.0 & $83^{*}$ & 6.5 \\
\hline 2(F) & $126.3^{*}$ & 9.6 & $82^{*}$ & 4.1 \\
\hline
\end{tabular}

SBP $P<0.05$

$\mathrm{DBP} * \mathrm{P}=0.02 * \mathrm{P}=0.01$

There was a significant reduction of blood pressure seen in 3 months of hemodialysis.

Table 10: Effect of hemodialysis on weight in CRF patients

\begin{tabular}{|c|c|c|}
\hline \multirow{2}{*}{ Group } & \multicolumn{2}{|c|}{ Weight (kgs) } \\
\cline { 2 - 3 } & Mean & SD \\
\hline 2(A) & 54.9 & 7.8 \\
\hline $2(\mathrm{~B})$ & 53.7 & 7.7 \\
\hline $2(\mathrm{C})$ & 53.4 & 7.4 \\
\hline $2(\mathrm{D})$ & 51.7 & 6.5 \\
\hline $2(\mathrm{E})$ & 50.7 & 6.1 \\
\hline $2(\mathrm{~F})$ & 50.3 & 6.2 \\
\hline
\end{tabular}

$P>0.05$

Though there was a mild reduction of weight within the group, it did not reveal any statistically significant value.

Table 11: Effect of hemodialysis on $\mathrm{Hb} \%$ in CRF patients

\begin{tabular}{|c|c|c|}
\hline \multirow{2}{*}{ Group } & \multicolumn{2}{|c|}{ HB \% } \\
\cline { 2 - 3 } & Mean & SD \\
\hline $2(\mathrm{~A})$ & 8.3 & 0.7 \\
\hline $2(\mathrm{~B})$ & 8.3 & 0.7 \\
\hline $2(\mathrm{C})$ & 8.7 & 0.7 \\
\hline $2(\mathrm{D})$ & 9.1 & $0.7^{*}$ \\
\hline $2(\mathrm{E})$ & 9.4 & $0.6^{*}$ \\
\hline $2(\mathrm{~F})$ & 9.6 & $0.5^{*}$ \\
\hline${ }^{*} \mathrm{p}=0.001,{ }^{*} \mathrm{p}=0.000$ & \multicolumn{2}{|c}{} \\
\hline
\end{tabular}

The Hemoglobin level was low in chronic renal failure patients with repeated dialysis the hemoglobin level improved on 3 months of hemodialysis.
Table 12: Effect of hemodialysis on blood urea level in CRF patients

\begin{tabular}{|c|c|c|}
\hline \multirow{2}{*}{ Group } & \multicolumn{2}{|c|}{ Blood Urea } \\
\cline { 2 - 3 } $2(\mathrm{~A})$ & Mean & SD \\
\hline $2(\mathrm{~B})$ & 104 & 7.3 \\
\hline $2(\mathrm{C})$ & 97.9 & 37.1 \\
\hline $2(\mathrm{D})$ & 88 & 26.4 \\
\hline $2(\mathrm{E})$ & 74.1 & $8.04^{*}$ \\
\hline $2(\mathrm{~F})$ & 62.2 & $14.4^{*}$ \\
\hline$* \mathrm{P}=0.002$ & 53.5 & $10.5^{*}$ \\
$* \mathrm{P}=0.000$ & \multicolumn{2}{|}{} \\
\hline \multicolumn{3}{|c}{} \\
\end{tabular}

The Blood Urea level was gradually reduced in subsequent dialysis and reached highly significant value after 3 months of hemodialysis.

Table 13: Effect of hemodialysis on serum creatinine in CRF patients

\begin{tabular}{|c|c|c|}
\hline \multirow{2}{*}{ Group } & \multicolumn{2}{|c|}{ Serum Creatinine } \\
\cline { 2 - 3 } & Mean & SD \\
\hline $2(\mathrm{~A})$ & 6.54 & 3.3 \\
\hline $2(\mathrm{~B})$ & 6.17 & 3.1 \\
\hline $2(\mathrm{C})$ & 5.61 & 2.8 \\
\hline $2(\mathrm{D})$ & 4.70 & 2.2 \\
\hline $2(\mathrm{E})$ & 3.82 & $1.9^{*}$ \\
\hline $2(\mathrm{~F})$ & 3.06 & $1.2^{*}$ \\
\hline $\mathrm{P}=0.005$ & \multicolumn{2}{|}{} \\
\hline
\end{tabular}

$* \mathrm{P}=0.000$

The Serum Creatinine level was high in pre-dialysis group and gradually reduced with repeated dialysis; the value showed highly significant reduction after 3 months of hemodialysis.

Table 14: Effect of hemodialysis on serum albumin in CRF patients

\begin{tabular}{|c|c|c|}
\hline \multirow{2}{*}{ Group } & \multicolumn{2}{|c|}{ Serum Serum Albumin (gms \%) } \\
\cline { 2 - 3 } & Mean & SD \\
\hline $2(\mathrm{~A})$ & 1.65 & 0.3 \\
\hline $2(\mathrm{~B})$ & 1.67 & 0.3 \\
\hline $2(\mathrm{C})$ & 1.81 & 0.3 \\
\hline $2(\mathrm{D})$ & 1.99 & 0.3 \\
\hline $2(\mathrm{E})$ & 2.26 & $0.3^{*}$ \\
\hline $2(\mathrm{~F})$ & 2.48 & $0.3^{*}$ \\
\hline
\end{tabular}

$* \mathrm{P}=0.004$

$* \mathrm{P}=0.000$

There was a reduction in Serum Albumin level in predialysis group when compared with 3 months of hemodialysis

Table 15: Effect of gender on lung parameter in CRF patient

\begin{tabular}{|c|c|c|c|c|}
\hline \multirow{2}{*}{ Parameter } & \multicolumn{2}{|c|}{ Male } & \multicolumn{2}{c|}{ Female } \\
\cline { 2 - 5 } & Mean & SD & Mean & SD \\
\hline VC & 2 & 0.49 & 1.28 & 0.46 \\
\hline FVC & 1.34 & 0.48 & 0.96 & 0.42 \\
\hline FEV1 & 1.66 & 0.45 & 1.12 & 0.45 \\
\hline FEV1\% & 79.61 & 3.01 & 78.75 & 2.86 \\
\hline PEF & 1.77 & 0.75 & 1.41 & 0.87 \\
\hline FEF 25-75\% & 1.55 & 0.41 & 1.01 & 0.36 \\
\hline
\end{tabular}

The lung function values were low in female patients than in male patients in chronic renal failure group. 
Table 16: Comparision of weight, \& blood parameters among group 1, 2(a) and 2 (f)

\begin{tabular}{|c|c|c|c|c|c|c|c|c|}
\hline \multirow{2}{*}{ Parameter } & \multicolumn{2}{|c|}{ Group 1} & \multicolumn{2}{|c|}{ Group 2(A) } & \multirow{2}{*}{$\begin{array}{c}\text { P Value } \\
\text { Value }\end{array}$} & \multicolumn{2}{|c|}{ Group 2 (F) } & \multirow{2}{*}{$\begin{array}{l}\text { P Value } \\
\text { Value }\end{array}$} \\
\hline & Mean & SD & Mean & SD & & Mean & SD & \\
\hline Weight (kgs) & 53.7 & 5.9 & 54.9 & 7.8 & 0.08 & 50.3 & 6.2 & 0.03 \\
\hline SBP (mmHg) & 125.6 & 7.6 & 140.7 & 32.2 & 0.001 & 126.3 & 9.6 & 0.7 \\
\hline HB \% (gms) & 83.6 & 4.5 & 90.67 & 11.1 & 0.04 & 82 & 4.1 & 0.1 \\
\hline DBP (gms) & 12.9 & 1 & 8.3 & 0.7 & 0 & 9.6 & 0.5 & 0 \\
\hline B. Urea (mgs) & 29.3 & 3.2 & 104 & 37.3 & 0 & 53.5 & 10.5 & 0 \\
\hline S. Creatinine (Mgs) & 0.95 & 0.2 & 6.54 & 3.3 & 0 & 3.06 & 1.2 & 0 \\
\hline S.A Albumin & 3.17 & 0.2 & 1.65 & 0.3 & 0 & 2.48 & 0.3 & 0 \\
\hline
\end{tabular}

In Chronic Renal Failure patients before dialysis body weight and blood pressure were increased than the control group which was reduced with regular dialysis.

The Blood Urea and Serum Creatinine levels significantly increases in Chronic Renal failure patients and decreases following dialysis but not reaching the normal level. Serum Albumin level were low in CRF patients which improved significantly with dialysis.

\section{Discussion}

The present study of pulmonary function test in chronic renal failure and the effect of hemodialysis on it were done on 30 healthy adults and 30 chronic renal failure patients in the age group of 45-60 years of both sex. The pulmonary function tests and other parameters were done for both control grciup and chronic renal failure patients who were not having any obvious lung disease. Chronic renal failure patients under went hemodialysis in the frequency of 3/week for a period of 3 months. Pulmonary function test was done Is' day, 1 week, 1 month, 2 months and 3 months duration of hemodialysis by using computerized spirometer along with the other parameters included in the study Weight, Blood pressure, HB\%, Blood Urea, Serum Creatinine and Serum Albumin.

This study has shown that the pulmonary function test like VC, FVC, FEV1, FEV1\%, PEF, FEF25-75\% were significantly lower in chronic renal failure patients than the control group. These findings have been well documented in many studies $[1,2,3,4,5]$. This may be the direct result of uremic toxins or may result indirectly from volume overload, anaemia, immune suppression, extraosseous disorders and acid-base imbalances, alterations in respiratory drive, mechanics of breathing, respiratory muscle function and gas exchange.

In our study there was no significant improvement in pulmonary function after a single dialysis. This may be due to single hemodialysis not being sufficient to remove the fluid which accumulated in the interstitial lung tissue. But a significant improvement in pulmonary

Function after a single dialysis ${ }^{[1]}$.

The present study has shown that improvement of FVC, FEVI, FEV 1\%, PEF and FEF 25-75\% following 1 week duration of hemodialysis. There is significant rise in their levels after 3months duration of repeated hemodialysis. Studies done earlier have shown similar findings ${ }^{[6,1,3]}$.

Though a mild increase in pulmonary function was observed with each dialysis, a significant improvement was seen after 3 months of repeated hemodialysis. The rise of pulmonary function values seems to contribute significant reduction of interstitial pulmonary edema followed by repeated hemodialysis.
In our study the body weight decreased with repeated hemodialysis. But the weight loss was not significant. Similar findings have been shown in other studies ${ }^{[1,7]}$. The weight loss has been due to loss of volume overload followed by repeated hemodialysis and loss of lean body mass with malnutrition.

According to Lazarus JM et al. ${ }^{[8]}$, Hypertension is present more than $80 \%$ of patients with CRF. Regular dialysis therapy is effective in controlling hypertension in the majority of CRF patients36. Our study showed that there was a high blood pressure in CRF and the mean BP was gradually decreased in repeated hemodialysis. The types of hypertension in chronic renal failure patients are (i) Volume dependent (ii) Renin dependent and (iii) Neurogenic hypertension. The reduction of blood pressure followed by repeated hemodialysis may be attributed to reduction in plasma volume, extracellular fluid volume and total exchangeable $\mathrm{Na}+$ as a result of ultra filtration.

In the present study HB\% level was low in CRF patients and there was a mild improvement of hemoglobin concentration followed by repeated hemodialysis. Another study ${ }^{[9]}$ has shown similar findings. Deficiency of erythropoietin is the main cause for anemia in most of the chronic renal failure patients.

Blood urea and Serum creatinine levels were high in all patients before dialysis treatment. During the first three months of dialysis technique, urea and creatinine level were significantly $(P<0.05)$ corrected but remained above the normal ranges. These data suggest the preservation of renal function and control of internal environment with dialysis therapy. These findings correlated with other study ${ }^{[9]}$.

The present study shows that the serum albumin levels were low in chronic renal failure and slight increase with repeated hemodialysis, but remained below the mean level of control group. Proteinuria, decreased albumin synthesis and hypercatabolism due to uremic intoxication are the causes for hypoalbuminemia in chronic renal failure patients. Other studies described that the serum level of albumin has been reduced in patients with hemodialysis [10, 11]. The inflammatory marker and restricted.

Protein intake are the predictors for hypoalbuminemia; hypercatabolism of albumin due to the influence of inflammatory markers in hemodialysis patients. According to Yang CS et al. ${ }^{[12]}$, increasing the dose of dialysis improves serum albumin levels. Many studies `were ${ }^{[13] ' \text { and }}$ ${ }^{\text {[12] }}$ showed an alternative interpretation of Serum Albumin level on dialysis therapy. This concept is intriguing and deserves further study.

The present study in chronic renal failure patients showed that the lung function values were low in females than in males. This finding correlated with other studies"' [14]. 


\section{Implications}

The findings of this study indicate that the pulmonary functions have improved alter 3-4 sittings of hemodialysis and further rise with 3 months duration of hemodialysis. The excess lung water is removed during the dialysis therapy; metabolic and electrolyte abnormalities are corrected, metabolic waste products are removed. The progression of chronic kidney disease to end stage renal disease is slowed significantly with the dialysis therapy. Dialysis therapy maintains the physical status of the renal failure patients to a normal range thus prolonging the life of the individual.

\section{Limitation}

This study has been carried out only in 30 chronic renal failure patients. A similar study with a large sample may yield better results and confirm the findings of this study. This study reflects only the effect of hemodialysis on lung function. The effect of other modalities of renal replacement therapy on pulmonary function has not been performed.

\section{Conclusion}

This study included only the effect of hemodialysis on lung function. A similar study of other modalities of renal replacement therapy may yield interesting results and also the effect of long term dialysis on pulmonary function in chronic renal failure patients may be under taken in future.

\section{Acknowledgement}

The author thankful to Department of Physiology, Shadan Institute of Medical Sciences, Hyderabad for providing all the facilities to carry out this work.

\section{References}

1. Tkacova R, Tkac I, Podracky J, Moscovic P, Roland R, Hilderbrand T. Spirometric alterations in patients with reduced renal function Weienklin, Wochenschr. 1993; 105(1):21-4.

2. Tang X, Wang Y, Tang L, Yuan Y. The influence of peritoneal dialysis on the pulmonary function of patients with end-stage renal disease. Hua Xi Yi Ke Da Xue Xue Bao. 2002; 33(1):123-4.

3. Alves J, Hespanhol V, Fernandes J, Marques EJ. Spirometric alterations caused by hemodialysis. Their relation to changes in the parameters commonly used to measure hemodialysis efficiency. Acta Med port. 1989; 2(4-5):195-8.

4. Putnam JS. The effect of hemodialysis on lung function, gas exchange, and response to carbon dioxide stimulation in chronic uremia - Am Med Sci. 1977; 273(1):87-95.

5. Will roth PO, Tredt Hi. Airway resistance in dialysis patients - Z Gesamte Inn Med. 1986; 41(2):48-50.

6. Fawcett S, Hoenich NA, Laker MF, Schorr W Jr, Ward Mk, Kerr DN. Haemodialysis- inducted respiratory changes. Nephrol Dial Transplant. 1987; 2(3):161-8.

7. Morrison JT, Willson AF, Vaziri ND. Brunsting L, Davis J. Determination of pulmonary tissure volume, pulmonary capillary blood flow and diffusing capacity of the lung before and after hemodialysis - Int J Artif Organs. 1980; 3(5):259-62.

8. Lazarus JM, Hampers CT, Merrill JP. Hypertension in chronic renal failure - Arch. Intern Med. 1974; 133:1059.
9. Stojimirovic B, Grujic-adanja G. The effect of hemodialysis and continuous ambulatory peritoneal dialysis on renal anemia - Srp Arh Celok Lek. 1997; 125(5-6):163-7.10.

10. Yeun JY Kaysen GA - Factors influenciniz, serum albumin in dialysis patients AM.J kidney disease. 1998; 32:S118-25.

11. Walshaw MJ, Lim R, Ahmad R, Hind CR. Bronchial reactivity in patients undergoing long-term haemodialysis for chronic renal failure. Blood Purif. 1991; 9(2):70-3.

12. Bhatia SL. The vital capacity of the lungs. Indian Med Gazette, 1929, 519-521.

13. American Throacic Society - Standardization of spirometry. Update. Am J Resg. \& Crit Care Med. 1994-1995; 152:1107-1136.

14. Kiyama T, Kinuwaki E, Tajiri M, Yamasaki T. Pulmonary function with acute loss of excess lung water by hemodialysis Kokyu to Junkan. 1977; 25(10):905-8. 